\title{
Influence of plaque composition on mechanisms of percutaneous transluminal coronary balloon angioplasty assessed by ultrasound imaging
}

\author{
Robert Gil, MD, Carlo Di Mario, MD, PhD, Francesco Prati, MD, Clemens von Birgelen, \\ Peter Ruygrok, MD, Jos R.T.C. Roelandt, $\mathrm{MD}, \mathrm{PhD}$, and Patrick W. Serruys, $\mathrm{MD}, \mathrm{PhD}$, with the \\ technical assistance of W.M. van Swijndregt and J. Ligthart Rotterdam, The Netherlands
}

\begin{abstract}
A.lthough percutaneous transluminal balloon angioplasty (PTCA) is now widely applied for treatment of coronary artery disease, our knowledge concerning the mechanism of angioplasty is limited and is mainly derived from in vitro studies. ${ }^{1-4}$ Intracoronary ultrasound (ICUS) offers a unique opportunity to study plaque composition in vivo, with a good correlation between ultrasonic and histologic plaque characteristics ${ }^{5-7}$ and to measure the changes in lumen and plaque area before and after coronary interventions. ${ }^{8,9}$ The elucidation of the operative mechanisms of PTCA in plaques with different preprocedural composition may lead to a targeted strategy for treatment of individual stenosis. In this study, serial ultrasound examinations were performed before and immediately after PTCA to assess the relations between lesion composition and distribution and mechanism of acute lumen enlargement after PTCA.
\end{abstract}

\section{METHODOLOGY}

Study group. Seventy-seven primary lesions in 77 patients (66 with one-vessel disease and 11 with two-vessel disease) treated with PTCA were examined in this study. The 62 men and 15 women ranged in age from 29 to 77 years (mean $58.1 \pm 10.8$ years). Forty-two $(54.5 \%)$ patients were treated because of

From the Intracoronary Imaging Laboratory and Cardiac Catheterization Laboratory, Thoraxcenter.

Dr. Gil is the recipient of the European Society of Cardiology Training Fellowship, 1994 (Sophia Antipolis-Nice). Dr. von Birgelen is the recipient of a Fellowship of the German Research Society (Deutsche Forschungs Gemeinschaft, Bonn)

Received for publication April 26, 1995; accepted June 8, 1995.

Reprint requests: Patrick Serruys, MD, PhD, Cardiac Catheterization Laboratory, Division of Cardiology, Thoraxcentre, BD 376, Erasmus University, P.O. Box 1738, 3015 GD Rotterdam, The Netherlands.

AM HEART J 1996;131:591-7.

Copyright $(1996$ by Mosby-Year Book, Inc. $0002-8703 / 96 / \$ 5.00+0 \quad \mathbf{4 / 1 / 6 9 4 9 1}$
Table I. Demographic and angiographic characteristics of the study patients.

$\begin{array}{lc}\text { Patients/lesions } & 77 / 77 \\ \text { Gender (M/F) } & 62 / 15 \\ \text { Mean age (yr; range) } & 51.8 \pm 10.8(29-77) \\ \text { Previous MI } & 8(10.4 \%) \\ \text { Diabetes mellitus } & 7(9.1 \%) \\ \text { Hypercholesterolemia } & 22(28.6 \%) \\ \text { Single/multivessel disease } & 66 / 11 \\ \text { Coronary syndrome } & \\ \quad \text { Stable/unstable } & 35 / 42 \\ \text { Vessel dilated } & \\ \text { LAD } & 37 \\ \text { LCX } & 17 \\ \text { RCA } & 23\end{array}$

$L A D$, Left anterior descending artery; $L C X$, left circumflex artery; $R C A$, right coronary artery.

unstable angina pectoris. An angiographically successful result $(<50 \%$ residual diameter stenosis measured with on-line quantitative angiography) was achieved in all patients. PTCA was performed in 37 left anterior descending artery lesions, 17 circumflex artery lesions, and 23 right coronary artery lesions. All patients signed a written informed consent form approved by the Medical Ethical Committee, Erasmus University/Dijkzigt Hospital. Basal demographic and angiographic characteristics are shown in Table I.

Angiographic assessment. Baseline angiograms were recorded in multiple views separated at least by 30 degrees of angulation before and after PTCA. An intracoronary bolus of isosorbide dinitrate ( 1 to $3 \mathrm{mg}$ ) was injected immediately before angiography. Quantitative coronary arteriography was performed with a previously described computer-assisted automatic quantitative analysis system (CAAS, Pie Data, Maastricht, The Netherlands) ${ }^{10}$ The presence or absence of calcium by fluoroscopy was noted. The presence and characteristics of angiographic dissections were 

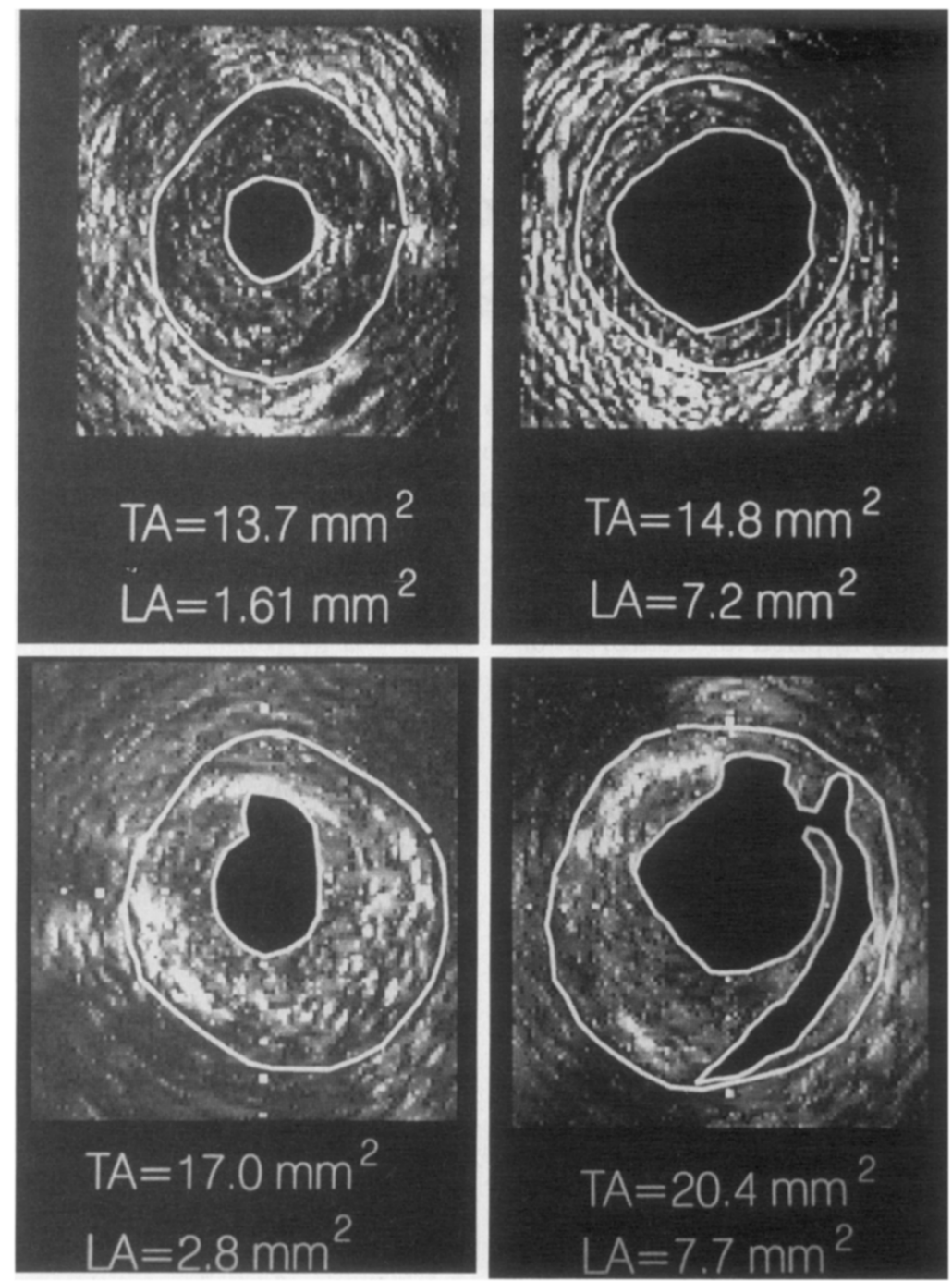

Fig. 1. Cross-sectional ultrasound images of target stenoses in left anterior descending coronary arteries classified as soft (top) and mixed (bottom) before (left) and immediately after PTCA (right). Lumen area corresponds to black central area; total area is contoured in white. Corresponding measurements (square millimeters) are reported below images. Note relatively bigger increase in total vessel area and practically no change in plaque area (calculated as difference between total vessel area [TA] and lumen area [LAJ) in mixed lesion in comparison to soft one.

defined according to the criteria of the National Heart, Lung, and Blood Institute PTCA Registry. ${ }^{11}$

Ultrasound assessment. ICUS examinations were performed before and after PTCA with a $4.3 \mathrm{~F}$ or $2.9 \mathrm{~F}$ mechanical ultrasound catheter operating at 30 $\mathrm{MHz}$ (CVIS, Sunnyvale, Calif.). The imaging probe was positioned distal to the target stenosis, and a manual continuous pullback was performed to obtain an initial assessment of the lesion. In 27 (35.1\%) patients, a second withdrawal of the ultrasound catheter was performed with a motorized pullback device at a constant speed of $1.0 \mathrm{~mm} / \mathrm{sec}$. By using reproducible anatomic landmarks (side branches or calcifications), comparable cross-sectional slices within the treated segment could be obtained before and after PTCA. There were no complications related to ultrasound imaging.

Ultrasonic image analysis. Qualitative and quantitative characteristics of the ultrasonic images were assessed by a consensus of two experienced observers. The plaque classification was based on its prevalent composition. Four types of plaque were distinguished: soft plaque: $>80 \%$ of the plaque area is composed of tissue with an echogenicity lower than the echogenicity of the adventitia (arc of lesion calcium <90 degrees); fibrous plaque: $>80 \%$ of the plaque area is composed of tissue, producing echoes as bright or brighter than the adventitia but without 
Table II. Plaque composition and procedural variables

\begin{tabular}{lccccc}
\hline $\begin{array}{c}\text { Plaque } \\
\text { type }\end{array}$ & $n$ & $\begin{array}{c}\text { Inflation time } \\
(\mathrm{sec})\end{array}$ & $\begin{array}{c}\text { Maximal BA pressure } \\
(\mathrm{atm})\end{array}$ & BA/A ratio & $\begin{array}{c}\text { ICUS presence of wall disruption } \\
\text { fracture/dissectiont }\end{array}$ \\
\hline Soft & 42 & $332.2 \pm 203.7$ & $9.0 \pm 3.15$ & $1.07 \pm 0.23$ & $18(42 \%) 5 / 13$ \\
Calcific & 11 & $414.2 \pm 349.9$ & $11.3 \pm 3.75^{*}$ & $1.12 \pm 0.18$ & $11(100 \%)^{*} 3 / 8$ \\
Mixed & 24 & $279.4 \pm 184.5$ & $9.81 \pm 2.70$ & $1.03 \pm 0.11$ & $17(70.8 \%) 1 / 16$ \\
\hline
\end{tabular}

$B A$, Angioplasty balloon; $B A / A$, balloon/artery ratio.

$*_{p}<0.05$, calcific vs soft.

†Lesions with fractures and dissections were considered only for more severe type of vessel wall disruption (dissection).

acoustic shadowing (arc of lesion calcium $<90$ degrees); diffuse calcified plaque: bright echoes within a plaque demonstrating acoustic shadowing and occupying more than 180 degrees of vessel wall circumference; mixed plaque: a plaque involving bright echoes with acoustic shadowing encompassing $>90$ degrees but $<180$ degrees of vessel wall circumference, or a mixture of soft and fibrous plaque with each component occupying $<80 \%$ of the plaque area.

The total circumferential calcium arc was measured and calcium localization distinguished between subendothelial (no plaque visible between calcium deposits and lumen) and deep (calcium deposits central and at the base of the plaque). An eccentricity index was calculated as the ratio between minimal and maximal wall thickness assessed before PTCA (not necessarily along the same diameter). Eccentric lesions were defined as lesions with an index $<0.5 .{ }^{12}$

Total vessel area was defined as the integrated area central to the medial-adventitial boundary. The boundary between the lumen and intima (leading edge) was used to define the lumen area. In case of wedging of the ultrasound probe in the stenosis before PTCA, a cross-sectional area of 1.61 or $0.72 \mathrm{~mm}^{2}$ of the $4.3 \mathrm{~F}$ and $2.9 \mathrm{~F}$ ultrasound probes, respectively, was used. Plaque area was defined as the difference between total vessel and lumen area. ${ }^{13}$ Fig. 1 presents measurements performed before and after PTCA in soft (top) and mixed lesions (bottom).

The presence and characteristics of wall disruption after PTCA were classified according to previously described criteria. ${ }^{12}$ Plaque fracture was classified as a rupture in a radial direction, and wall dissection was defined as a plaque rupture in a tangential direction. The presence of blood speckles inside the newly formed lumen and the effect of vigorous flushing with contrast medium or saline were used to distinguish artifacts from true wall disruptions.

Statistics. Data are presented as mean \pm SD. A two-tailed Student's $t$ test for paired data was used to compare differences in the parameters character-
Table III. ICUS area measurements before and after balloon angioplasty

\begin{tabular}{lccl}
\hline & \multicolumn{2}{c}{ PTCA } & \\
\cline { 2 - 3 } \multicolumn{1}{c}{ Parameter } & Before & After & \\
\cline { 2 - 3 } \multicolumn{1}{c}{ LA ref $\left(\mathrm{mm}^{2}\right)$} & $9.08 \pm 3.04$ & $9.29 \pm 3.03$ & NS \\
TA ref $\left(\mathrm{mm}^{2}\right)$ & $17.33 \pm 5.09$ & $17.61 \pm 5.07$ & NS \\
PLA ref $\left(\mathrm{mm}^{2}\right)$ & $8.24 \pm 3.42$ & $8.32 \pm 3.52$ & NS \\
AS ref $(\%)$ & $46.50 \pm 12.29$ & $46.25 \pm 12.35$ & NS \\
LA sten $\left(\mathrm{mm}^{2}\right)$ & $1.94 \pm 0.81$ & $5.40 \pm 1.59$ & 0.000001 \\
TA sten $\left(\mathrm{mm}^{2}\right)$ & $15.40 \pm 4.68$ & $17.1 \pm 4.77$ & 0.03 \\
PLA sten $\left(\mathrm{mm}^{2}\right)$ & $13.44 \pm 4.59$ & $11.74 \pm 4.77$ & 0.02 \\
AS $(\%)$ & $86.45 \pm 5.99$ & $67.21 \pm 8.79$ & 0.000001 \\
\hline
\end{tabular}

$L A$, Lumen area; ref, reference segment; $T A$, total vessel area; $P A$, plaque area; $A S$, percentage area of stenosis; sten, stenosis.

izing the mechanisms of acute results after PTCA according to preintervention plaque composition and presence of fracture/dissection after PTCA. A chisquared test was used to compare differences among qualitative variables. Regression analysis was used to assess the correlation between quantitative ultrasonic measurements and acute changes after PTCA. A $p$ value of $<0.05$ was considered to be significant.

\section{OBSERVATIONS}

Procedure. There was no significant difference in terms of balloon/artery ratio and time of balloon inflation among plaques of different ultrasonic characteristics. However, a trend toward longer duration of balloon inflation and significantly higher balloon pressure was found for diffusely calcified lesions (Table II). No clear influence of balloon/artery ratio, time of balloon inflation, and maximal balloon pressure on vessel lumen and plaque after PTCA was found. Only significant correlations between balloon/ artery ratio, and postprocedural total vessel and plaque areas changes were found for mixed lesions $(r=-0.58$ and $r=0.61$, respectively, $p<0.05$ ).

Angiographic analysis. Calcium was identified in the target stenosis by angiography in $8(10.4 \%)$ cases. The preprocedural minimal lumen diameter and percent area stenosis $(1.11 \pm 0.3 \mathrm{~mm}$ and 


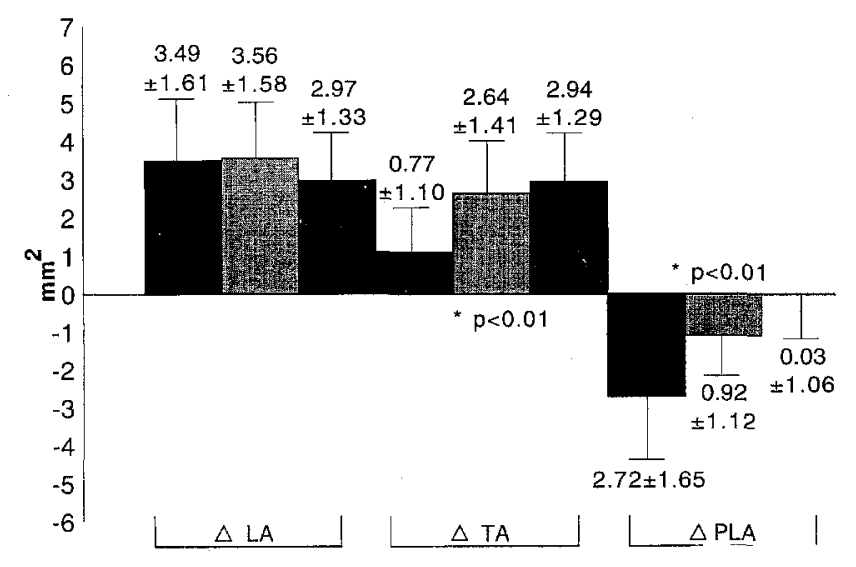

Fig. 2. Lumen area (LA), total area (TA), and plaque area (PLA) changes from before to after PTCA are distinguished according to prevalent plaque composition. Although no significant differences in acute lumen gain were observed, soft plaques (black bars) appear to have larger plaque reduction and smaller vessel expansion compared with mixed (light gray bars) and calcific (dark gray bars) plaques.

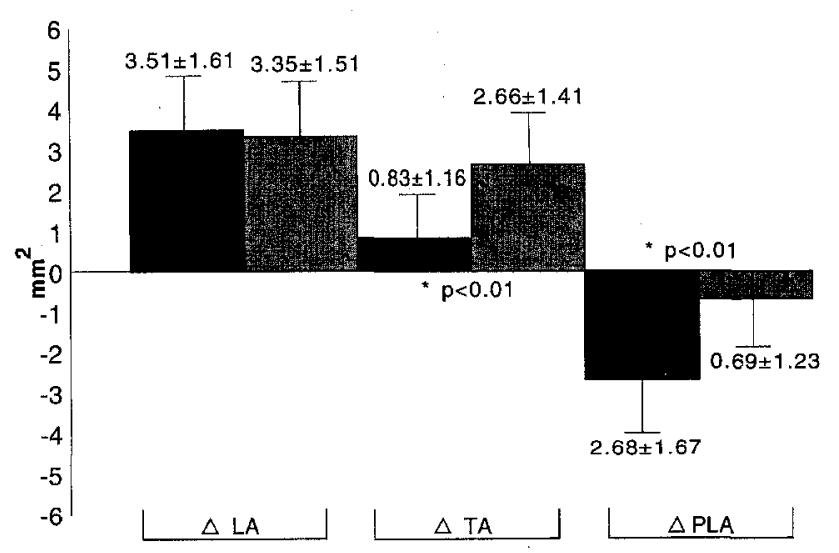

Fig. 3. Lumen, plaque, and total area changes from before to after PTCA in arteries with total arc of lesion calcium $>90$ degrees (gray bars) and $\leq 90$ degrees (black bars). Note significantly larger increase in total area in group, with total arc $>90$ degrees. Abbreviations as in Fig. 2.

$82.6 \% \pm 10 \%$, respectively) were significantly improved $(p<0.00001)$ after PTCA $(1.98 \pm 0.4 \mathrm{~mm}$ and $50.7 \% \pm 16.4 \%$, respectively). A National Heart, Lung, and Blood Institute Registry class B or C angiographic dissection was present in $17(22.1 \%)$ of 77 patients.

Qualitative ultrasound analysis. By ultrasound, 42 (54.5\%) lesions were classified as soft, none as fibrous, 11 (14.3\%) as diffuse calcific, and $24(31.2 \%)$ as mixed. Twenty-three (29.9\%) lesions were concentric. Fifty-nine (76.6\%) of 77 lesions showed focal or diffuse areas of calcification. In 21 (35.6\%) cases, calcium localization was defined as subendothelial and in $38(64.4 \%)$ cases as deep.

The presence of fracture and dissection was found in $9(11.7 \%)$ and $37(48 \%)$ of cases, respectively. All of the 11 diffusely calcific plaques (100\%), $17(70.8 \%)$ of 24 mixed plaques and $18(42.8 \%)$ of 42 soft plaques developed fractures or dissections after PTCA (Table II). Focal deposits of calcium were present in all but three of the predominantly soft plaques which developed fracture or dissection after PTCA.

Quantitative ultrasound analysis. Table III reports the changes in lumen, total vessel, and plaque areas from before to after PTCA. Before PTCA, the ultrasound probe was wedged in the lesion in $75.3 \%$ of cases (58 of 77). After PTCA, the minimal cross-sectional lumen area of the target stenosis increased significantly for all treated lesions. Total vessel area for the studied group increased significantly by $1.7 \pm 1.66 \mathrm{~mm}^{2}$, which accounts for $48.9 \%$ of the immediate lumen gain. Plaque area decreased significantly by $1.75 \pm 1.89 \mathrm{~mm}^{2}$, accounting for the remaining $51.1 \%$ of the immediate lumen gain.

There was no significant difference in acute lumen gain according to plaque composition, although a 
smaller lumen enlargement was achieved in diffusely calcified lesions than in soft or mixed lesions (Fig. 2). A greater acute lumen gain was obtained in concentric than in eccentric lesions $(3.60 \pm 1.57 \mathrm{vs}$ $3.37 \pm 1.40$, not significant [NS], respectively). Postprocedural lesion morphologic features (presence fracture and/or dissection) could not be demonstrated to significantly affect the mechanisms of acute lumen enlargement.

In soft lesions, lumen gain was predominantly associated with plaque reduction $(77.9 \%)$, whereas in calcified and mixed lesions the main operative mechanism was vessel expansion $(99.1 \%$ and $74.2 \%$, respectively, NS; Fig. 2). There was no significant difference in acute lumen gain in plaques with subendothelial and deep calcifications $\left(3.37 \pm 1.57 \mathrm{~mm}^{2}\right.$ vs $3.55 \pm 1.56 \mathrm{~mm}^{2}$, respectively, NS). In the lesions with total arc of calcium $>90$ degrees the main contribution to post-PTCA lumen enlargement was vessel expansion (79.3\%). On the contrary, in lesions with a smaller total arc of calcification, plaque reduction (76.2\%) was the predominant mechanism (Fig. 3). The magnitude of total arc of lesion calcification showed a positive correlation with the increase in total vessel area $(r=0.45, p<0.05)$ and an inverse correlation with plaque reduction $(r=-0.50$, $p<0.05$; Fig. $4, A$ and $B$, respectively).

There was no significant correlation between lesion eccentricity and total vessel, lumen, and plaque area changes after PTCA for all the lesions studied. However, a trend toward greater plaque reduction in concentric lesions was found when concentric lesions were compared with eccentric lesions (acute lumen gain of $58.3 \%$ vs $48.5 \%$, respectively).

\section{COMMENTS}

Since its introduction into clinical practice, many theories regarding the operative mechanism of coronary balloon angioplasty have been proposed. Initially, compression and redistribution of the atherosclerotic plaque was postulated as the main mechanism of lumen enlargement after PTCA. ${ }^{14,15}$ Histologic studies indicated that rupture of vessel wall components and overstretching of the arterial wall were almost invariably associated with balloon dilatation. ${ }^{1,3}$ For a long time these hypotheses were based on animal studies ${ }^{16,17}$ or in vitro studies on postmortem specimens. ${ }^{1-3}$ However, plaque characteristics in experimental atherosclerosis are very different from the characteristics of human plaques and pathologic specimens obtained from patients with an unfavorable outcome after coronary interventions and are not representative of the entire spectrum of morphologic changes that occur after

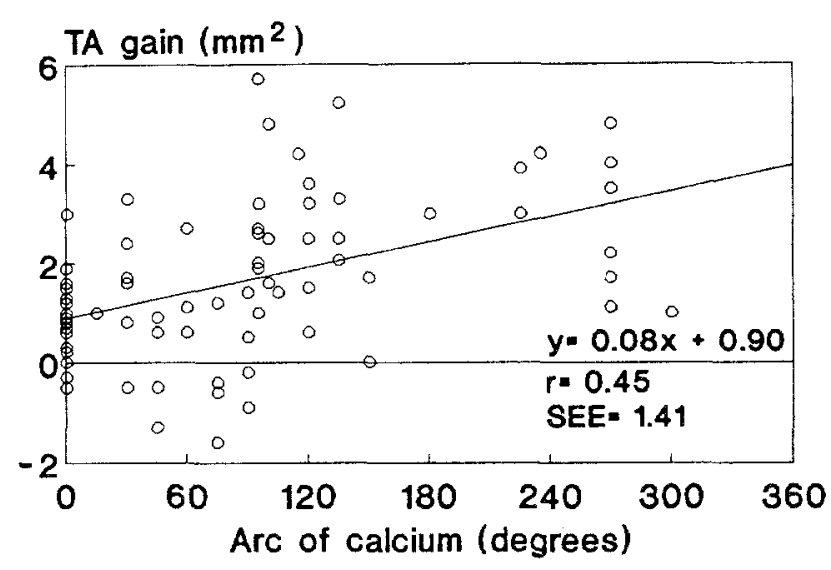

A

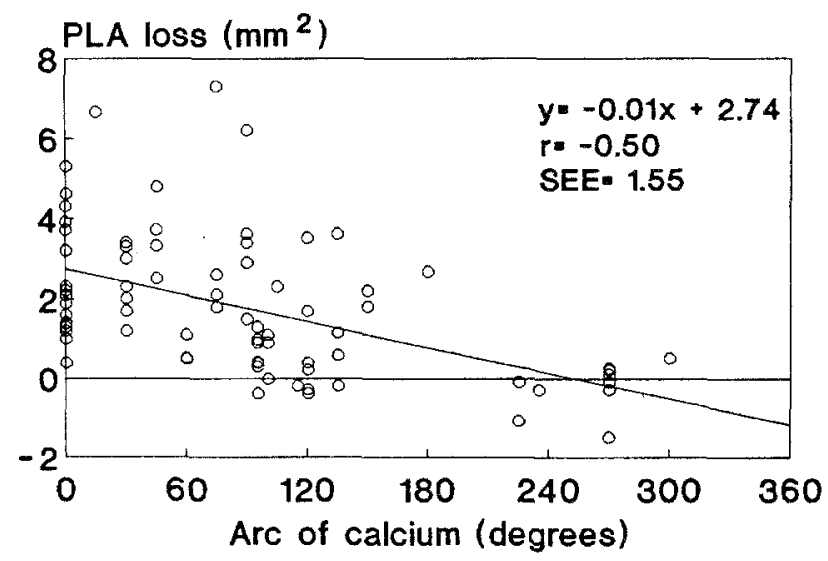

$\mathbf{E}$

Fig. 4. Plots of changes in total vessel (A) and plaque (B) areas depending on total arc of lesion calcium. Abbreviations as in Fig. 2.

PTCA. Although coronary quantitative angiography has been established as a gold standard for the assessment of coronary stenosis severity, this technique has clear limitations for the assessment of coronary interventions because the presence of complex wall injury modifies the circular geometry of the lumen, which is prerequisite for precise measurements. ${ }^{18-20}$ ICUS is the only coronary imaging technique that can directly study plaque composition and distribution in vivo. ${ }^{5,6}$ Moreover, this technique is more sensitive than angiography in the detection of the presence of calcification and vessel wall disruption $^{4,7,21}$ and can quantitatively assess the changes in lumen and plaque area before and after interventions. ${ }^{8,9}$ Because of these features, ICUS has the potential to elucidate the mechanisms of successful coronary intervention. Recent ICUS studies have confirmed that PTCA induces vessel wall fractures 
or dissections in the majority of cases and that the main mechanism of lumen enlargement is total vessel area expansion. ${ }^{19,22-24}$ The study of Botas et al. ${ }^{25}$ has shown that coronary distensibility increases after PTCA as a result of releasing outer vessel wall from the cicatrizing effects of the noncompliant atherosclerotic intimal plaque.

The present study has shown that vessel expansion is responsible for half the lumen enlargement after PTCA. More interesting is that, in our study a correlation between the composition of atherosclerotic plaque and mechanisms of balloon dilatation was observed. A reduction in plaque area was the main operative mechanism in lesions with soft plaque, whereas expansion of the total vessel area was the predominant mechanism of lumen area increase in lesions with calcified and mixed plaques. In particular, as shown in previous studies, ${ }^{4,26}$ the presence and amount of calcium deposits significantly influenced the development of vessel wall disruptions. In lesions with an extensive amount of calcium, a partial vessel rupture is essential for successful balloon dilatation because the rigid plaque structure does not allow compression as occurs in the presence of thrombi or fibrofatty lesions. Our study has shown also that, despite a satisfactory immediate postprocedural lumen gain, an enormous residual plaque burden remains that undoubtedly contributes to the high rate of restenosis after PTCA. ${ }^{4,27}$

Despite these different mechanisms, the final lumen enlargement was similar in soft and mixed lesions and only slightly smaller in diffusely calcified plaques. Plaque calcification therefore appears to be only a partial contraindication to PTCA but does require higher balloon pressures to achieve results comparable to the results obtained in noncalcified plaques and is associated with a high prevalence of wall fractures and/or dissections.

Study limitations. This study was based on the analysis of serial cross-sectional images obtained most often during a manual withdrawal of the ultrasound catheter along the vessel. The use of three-dimensional reconstruction of consecutive transverse images obtained during a motorized pullback may enhance precise morphologic classification of the lesion, lumen geometry, and plaque burden. It may decrease variability of all dimensional measurements. Moreover, axial plaque redistribution can be assessed by calculating changes in plaque volume. ${ }^{28}$

Conclusion. Plaque composition and distribution is a major determinant of the mechanisms of PTCA. Plaque compression and/or axial redistribution is the main mechanism of PTCA in soft plaque, whereas wall disruption and total vessel expansion is predominant in mixed and calcified plaques.

\section{SUMMARY}

In this study the influence of plaque composition on mechanism of immediate lumen enlargement after PTCA were assessed by serial ultrasound imaging in 77 patients. According to the preprocedural ultrasonic plaque characteristics, the lesions were classified as soft (54.5\%), diffusely calcified (14.3\%), and mixed $(31.2 \%)$. The total arc of calcium and plaque eccentricity were also calculated. The mean balloon/artery ratio was equal for all types of lesions (1.07 \pm 0.19 ), but diffusely calcified lesions required a higher maximal balloon inflation pressure $(11.3 \pm 3.75 \mathrm{~atm}$ vs $9.0 \pm 3.15 \mathrm{~atm}$ for calcified and soft lesions, respectively, $p<0.05$ ). The increase in lumen area after PTCA was similar in soft and mixed lesions $\left(3.49 \pm 1.61 \mathrm{~mm}^{2}\right.$ vs $\left.3.56 \pm 1.58 \mathrm{~mm}^{2}, \mathrm{NS}\right)$ and was slightly lower in diffusely calcified lesions $\left(2.97 \pm 1.33 \mathrm{~mm}^{2}, \mathrm{NS}\right)$. Reduction in plaque area was the main operative mechanism in lesions with soft plaque, explaining $77.9 \%$ of the acute lumen gain. Expansion of the total vessel area was the predominant mechanism of lumen area increase in lesions with calcified and mixed plaques $(99.1 \%$ vs $74.2 \%$, respectively, NS). In particular, lesions with a total arc of calcium $>90$ degrees showed a high prevalence of vessel expansion as a mechanism of lumen enlargement compared with lesions with a calcium arc $<90^{\circ}(79.3 \%$ vs $23.8 \%$, respectively, $p<0.05)$. In the studied group, presence of calcification was highly associated with wall fracture and dissection after balloon dilatation $(93.4 \%$ vs $6.6 \%$ in lesions with and without calcifications, respectively, $p<0.05$ ). A trend toward a greater degree of plaque reduction in concentric lesions in comparison to eccentric lesions was observed ( $58.3 \%$ vs $48.5 \%$, respectively, NS). In conclusion, immediate lumen enlargement after PTCA does not differ for soft and mixed plaques. Diffusely calcific plaques show a smaller lumen enlargement despite a higher balloon inflation pressure. Plaque compression or axial redistribution is the main operative mechanism of PTCA in soft plaques, whereas an increase in total vessel area determines the lumen. enlargement in mixed/calcific plaques. Plaque fracture or wall dissection is almost invariably associated with presence of plaque calcification.

\section{REFERENCES}

1. Lyon RT, Zarins ChK, Lu Ch-T, Yang Ch-F, Glagov S. Vessel, plaque, and lumen morphology after transluminal balloon angioplasty. Quantitative study in distended human arteries. Arteriosclerosis 1987;7:30614.

2. Waller BF, Gorfinkel HJ, Rogers FJ, Kent KM, Roberts WC. Farly and 
late morphologic changes in major epicardial coronary arteries after percutaneous transluminal coronary angioplasty. Am J Cardiol 1984; 53:42-7C.

3. Farb A, Virmani R, Atkinson JB, Kolodgie FD. Plaque morphology and pathologic changes in arteries from patients dying after coronary balloon angioplasty. J Am Coll Cardiol 1990;16:1421-9.

4. Virmani R, Farb A, Burke AP. Coronary angioplasty from the perspective of atherosclerotic plaque: morphologic predictors of immediate success and restenosis. AM HEART J 1994;127:1:163-79.

5. Di Mario C, The SHK, Madretsma S, van Suylen RJ, Wilson RA, Boom N, Serruys PW, Gussenhoven EJ, Roelandt JRTC, Zhong Y, Wenguang L. Detection and characterization of vascular lesions by intravascular ultrasound: an in vitro study correlated with histology. J Am Soc Echocardiogr 1992;5:135-46.

6. Gussenhoven EJ, Essed CE, Lancee CT, Matik F, Frietman P, van Egmond FC, Reiber J, Bosch H., van Urk H, Roelandt JRTC, Bom N. Arterial wall characteristics determined by intravascular ultrasound imaging: an in vitro study. J Am Coll Cardiol 1989;14:947-52.

7. Friedrich GJ, Moes NY, Mühlberger VA, Gabl Ch, Mikuz G, Hausmann D, Fitzgerald PJ, Yock PG. Detection of intralesional calcium by intracoronary ultrasound depends on the histologic pattern. AM HEART J 1994; 128:435-41.

8. Losordo DW, Rosenfield K, Pieczek A, Baker K, Harding M, Isner JM. How does angioplasty work? Serial analysis of human iliac arteries using intravascular ultrasound. Circulation 1992;86:1845-58.

9. The SHK, Gussenhoven EJ, Zhong Y, Li W, van Egmond F, Pieterman H, van Urk H, Gerritsen P, Borst C, Wilson RA, Bom N. Effect of balloon angioplasty on femoral artery evaluated with intravascular ultrasound imaging. Circulation 1992;86:483-93.

10. Haase J, Di Mario C, Slager CJ, van der Giessen WJ, den Boer A, de Feyter PJ, Reiber JHC, Verdouw PD, Serruys PW. In-vivo validation of on-line and off-line geometric coronary measurements using insertion of stenosis phantoms in porcine coronary arteries. Cathet Cardiovasc Diagn 1992;27:16-27.

11. Dorros G, Cowley MJ, Simpson J, Bentiviglio LG, Block PC, Boroussa M, Detre K, Gosselin AJ, Gruentzig AR, Kelsey SF, Kent KM, Mock MB, Mullin SM, Myler RK, Passmani ER, Stertzer SH, Williams DO. Percutaneous transluminal coronary angioplasty: report of complications from the National Heart, Lung, and Blood Institute PTCA registry. Circulation 1983;67:723-30.

12. Honye J, Mahon DJ, White CJ, Ramee SR, Tobis JM. Morphological effects of coronary balloon angioplasty in vivo assessed by intravascular ultrasound imaging. Circulation 1992;85:1012-25.

13. Hodgson McJB, Reddy KG, Suneja R, Nair RN, Lesnefsky EJ, Sheehan HM. Intracoronary ultrasound imaging: correlation of plaque morphology with angiography, clinical syndrome and procedural results in patients undergoing coronary angioplasty. J Am Coll Cardiol 1993;21:3544.

14. Dotter CT, Judkins MP. Transluminal treatment of atherosclerotic obstructions: description of a new technique and preliminary report of its application. Circulation 1964;30:654-70.
15. Gruentzig AR. Transluminal dilatation of coronary artery stenosis. Lancet 1978;1:263-7.

16. Sunborn TA, Faxon DP, Haudenschjld Ch, Gottsman SB, Ryan TJ. The mechanism of transluminal angioplasty: evidence for formation of aneurysm in experimental atherosclerosis. Circulation 1983;68:113640.

17. Fischell TA, Grant G, Johnson DE. Determinants of smooth muscle injury during balloon angioplasty. Circulation 1990;82:2170-84.

18. Haase J, Ozaki Y, Di Mario C, Escaned J, de Feyter PJ, Roelandt JRTC, Serruys PW. Can intracoronary ultrasound correctly assess the luminal dimensions of coronary artery lesions? A comparison with quantitative angiography. Eur Heart J 1995;16:112-9.

19. Nakamura S, Mahon DJ, Maheswaran B, Gutfinger DE, Colombo A, Tobis JM. An explanation for discrepancy between angiographic and intravascular ultrasound measurements after percutaneous transluminal coronary angioplasty. J Am Coll Cardiol 1995;25:633-9.

20. De Scheerder I, De Man F, Herregods MC, Wilczek Larrios L, Raymenants E, Desmet W, De Geest H, Piessens J. Intravascular ultrasound versus angiography for measurement of luminal diameters in normal and diseased coronary arteries. AM HEART I 1994;127:24351.

21. Mintz GS, Douek P, Pichard AD, Kent KM, Satler LF, Popma JJ, Leon MB. Target lesion calcification in coronary artery disease: an intravascular ultrasound study. J Am Coll Cardiol 1994;22:1149-55.

22. Tenaglia AN, Buller CE, Kisslo KB, Stack RS, Davidson CJ. Mechanisms of balloon angioplasty and directional coronary atherectomy as assessed by intracoronary ultrasound. J Am Coll Cardiol 1992;20:68591.

23. Braden GA, Herrington DM, Downes TR, Kutcher MA, Little WC. Qualitative and quantitative contrasts in the mechanisms of lumen enlargement by coronary balloon angioplasty and directional coronary atherectomy. J Am Coll Cardiol 1994;23:40-8.

24. Di Mario C, Gil R, Camenzind E, Ozaki Y, Birgelen von C, Umans V, Jaegere de P, Feyter de PJ, Roelandt JRTC, Serruys PW. Quantitative assessment with intracoronary ultrasound of the mechanisms of restenosis after percutaneous transiuminal balloon angioplasty and directional coronary atherectomy. Am J Cardiol 1995;75:772-7.

25. Botas J, Clark DA, Pinto F, Chenzbraun A, Fischell TA. Balloon angioplasty results in increased segmental coronary distensibility: a likely mechanism of percutaneous transluminal coronary angioplasty. J Am Coll Cardiol 1994;23:1043-52.

26. Fitzgerald PJ, Ports TA, Yock PG. Contribution of localized calcium deposits to dissection after angioplasty in vivo assessed by intravascular ultrasound imaging. Circulation 1992;86:64-70.

27. Jain SP, Jain A, Collins TJ, Ramee SR, White ChJ. Predictors of restenosis: a morphometric and quantitative evaluation by intravascular ultrasound. AM HEART J 1994;128:664-73.

28. Roelandt JRTC, Di Mario C, Pandian NG, Wenguang L, Keane D, Slager CJ, de Feyter PJ, Serruys PW. Three-dimensional reconstruction of intracoronary ultrasound images. Rationale, approaches, problems and directions. Circulation 1994;90:1044-55. 